\title{
Effects of Antarctic krill oil on lipid and glucose metabolism in C57BL/6J mice fed with high fat diet
}

\author{
Dewei Sun, Liang Zhang, Hongjian Chen, Rong Feng, Peirang Cao* and Yuanfa Liu* (D)
}

\begin{abstract}
Background: Obesity and other metabolic diseases have become epidemic which greatly affect human health. Diets with healthy nutrition are efficient means to prevent this epidemic occurrence. Novel food resources and process technology were needed for these purpose. In this study, Antarctic krill oil (KO) extracted from a dry krill by a procedure of hot pump dehydration in combined with freezing-drying was used to investigate health effect in animals including the growth, lipid and glucose metabolism.
\end{abstract}

Methods: C57BL/6J mice were fed with a lard based high fat (HF) diet and substituted with KO for a period of 12 weeks in comparison with low fat normal control (NC) diet. Mice body weight and food consumption were recorded. Serum lipid metabolism - of C57BL/6J mice serum was measured. A glucose tolerance tests (GTTs) and pathology analysis of mice were performed at the end of the experiment.

Results: The KO fed mice had less body weight gain, less fat accumulation in tissue such as adipose and liver. Dyslipidemia induced by high fat diet was partially improved by $\mathrm{KO}$ feeding with significant reduction of serum low density lipoprotein-cholesterol (LDL-C) content. Furthermore, $\mathrm{KO}$ feeding also improved glucose metabolism in C57BL/6J mice including a glucose tolerance of about $22 \%$ vs. $32 \%$ of AUC (area under the curve) for KO vs HF diet and the fast blood glucose level of $8.5 \mathrm{mmol} / \mathrm{L}, 9.8 \mathrm{mmol} / \mathrm{L}$ and $9.3 \mathrm{mmol} / \mathrm{L}$ for $\mathrm{NC}, \mathrm{HF}$ and $\mathrm{KO}$ diet groups, respectively. In addition, $\mathrm{KO}$ feeding also reduced oxidative damage in liver with a decrease of malondialdehyde (MDA) content and increase of superoxide dismutase (SOD) content.

Conclusion: This study provided evidence of the beneficial effects of $\mathrm{KO}$ on animal health from the processed technology, particularly on lipid and glucose metabolism. This study confirmed that as the Antarctic krill was extracted with a procedure of efficient energy, it might make it possible for Krill oil to be available for food industry.

Keywords: Antarctic Krill oil, EPA and DHA, C57BL/6J mice, Lipid metabolism, Glucose tolerance

\section{Background}

Obesity and diabetes become epidemic and a major burden for public health in the developed countries and in the world. Individuals with obesity are at a higher risk of chronic diseases including cardiovascular diseases, nonalcoholic fatty liver disease, type 2 diabetes [1] and other metabolic syndromes.

Obesity is associated with intrahepatic lipid accumulation, which has been linked to the development of insulin

\footnotetext{
* Correspondence: prcao@jiangnan.edu.cn; yfliu@jiangnan.edu.cn

State Key Laboratory of Food Science and Technology, Synergetic Innovation Center of Food Safety and Nutrition, School of Food Science and

Technology, Jiangnan University, 1800 Lihu Avenue, Wuxi, Jiangsu 214122, People's Republic of China
}

resistance and metabolic dysfunction, eventually to an occurrence of diabetes. Lifestyle factors such as diet and physical activity influence obesity through change of adiposity and insulin resistance. Diets with proper food ingredients have great impact on the health of population, such as supplementation with nutraceuticals. Unsaturated fatty acid supplementation, particularly of marine-derived oils from fish, seaweed, microalgae and Antarctic krill, have been popular for their high contents of fatty acid docosahexaenoic acid (DHA, 22:6 $\omega 3$ ) and eicosapentaenoic acid (EPA, 20:5 $\omega 3$ ). These $n-3$ fatty acids have been documented for their protective effects on cardiovascular diseases, diabetes and chronic metabolic diseases [2]. 
Krill is an increasingly important source of n-3 PUFAs as Krill oil has high EPA and DHA-containing phospholipids which might be better bioavailability with some uncertainty [3]. KO has a significant amount of astaxanthin, an important natural antioxidative component [4]. Intake of food rich in antioxidants is beneficial to reduce the risk of the cardiovascular, high blood pressure and cancer [5]. $\mathrm{KO}$ in animal feeding with high fat diet has been demonstrated to improve its dyslipidemia, body weight and glucose metabolism [6-8]. KO containing diets can significantly improve fast blood glucose concentration and glucose intolerance leading to enhance insulin sensitivities in obese animals [8-10].

$\mathrm{KO}$ as a food supplementation has become popular with some pilot trials indicating healthy benefits [11]. Beuy et al., had reviewed the biological function of the $\mathrm{KO}$, and pointed out that KO seems to be good marine food supplementation but there is still no concrete conclusive on clinical efficacy in the management of chronic metabolic diseases [12].

As Antarctic krill is a huge bio-resource of value food oil with less polluted, proper technology development is needed for exploration as nutrient supplementation for food industry. This lab had developed a novel preservation procedure for Antarctic krill with energy efficiency and could be applied in a large scale for food industry [13]. Since the different technologies could greatly impact oil properties and healthy effect as well, in this study, the aim was to investigate the effects of $\mathrm{KO}$, extracted from Antarctic krill using a drying procedure with energy efficiency on C57BL/6J mice with experimentally induced obesity. The mice fed with high fat diet, substituent of $\mathrm{KO}$ in contrast to normal chow diet showed that $\mathrm{KO}$ diet could reduce animal body weight gain and improve dyslipidemia, glucose metabolism as well as oxidative damage.

\section{Methods}

\section{KO preparation and reagents}

Frozen Antarctic krill were provided by Liaoning Province Dalian Ocean Fishery Group of Corporations (Dalian, China) and dried by hot pump dehydration system (HGOE-10/s, Hangzhou Ouyi Electric Co., Ltd., Hangzhou, China) combined with freezing-drying procedure [13]. $\mathrm{KO}$ was extracted by a subcritical extraction system (CBE-5 L, Henan Yalinjie Biological Technology Co., Ltd., Anyang, China) using butane as subcritical fluid, then stored at $-40{ }^{\circ} \mathrm{C}$ for further use.

Fatty acid methyl ester standards were purchased from Sigma-Aldrich (St. Louis, USA). Hematoxylin and eosin were obtained from Nanjing Jiancheng Bioengineering Institute (Nanjing, China). All other reagents were analytical grade and purchased from Sinopharm Chemical Reagent Co., Ltd. (Shanghai, China).

\section{KO profile analysis}

Peroxide Value (POV) was performed according to the American Oil Chemists' Society (AOCS) Method Cd 8-53 [14]. Fatty acids analysis was evaluated by fatty acid derivatives of methyl ester, and detected by Gas chromatography according to the method of AOCS [15]. PLs were measured by an HPLC system (Waters 600) equipped with a UV detector (Waters-2487, USA) according to the method by Jiang et al. [16]. Tocopherol content was determined and quantified by using an HPLC system (LC-20AT, Shimadzu, Japan) according to AOCS Method Ce 8-89 [17], and the contents were reported in $\mathrm{mg} / \mathrm{kg}$.

Astaxanthin content was measured by using a UV spectrophotometer (Alpha-1500, Shanghai Puyuan instrument Co. Ltd., Shanghai, China) according to the method of Tolasa and Brown et al. $[18,19]$. Astaxanthin concentration was calculated from the standard curve of astaxanthin [18].

\section{Animals and diets}

In this study, 30 male C57BL/6J mice (SLRC Laboratory Animal, Shanghai, China) at 6 weeks of age were randomly divided into 3 groups after being fed with normal rodent chow (SLRC Laboratory Animal, Shanghai, China) for a week for acclimation. Mice were fed with following diets: normal low-fat chow diet, lard based high fat diet and $\mathrm{KO}$ containing high fat diet as indicated in Table 3. The mice were kept in an environmentally controlled room (temperature, $25 \pm 2{ }^{\circ} \mathrm{C}$; humidity, $60 \pm 5 \%$; $12 \mathrm{~h}$ light-dark cycle) with free access to food and water.

Mice body weight and food consumption were recorded every week and every another day, respectively. Blood HDL and LDL were monitored biweekly through retroorbital blooding. After being fed with the respective diets for about 12 weeks, the mice were sacrificed. Final body and organ weight were recorded. Mouse blood was collected and serum was separated by centrifugation at $800 \times \mathrm{g}$ for $15 \mathrm{~min}$ at $4{ }^{\circ} \mathrm{C}$. Liver and other organs were removed and snap frozen in liquid $\mathrm{N}_{2}$. All samples were stored at $-80{ }^{\circ} \mathrm{C}$ freezer for further analysis.

\section{Glucose tolerance tests (GTTs)}

A GTTs was performed after mice were fasted for $6 \mathrm{~h}$ at the end of the experiment. Tail blood was collected before $(0 \mathrm{~min})$ and at $30,60,90$, and $120 \mathrm{~min}$ after administration of a $10.0 \%$ D-glucose solution $(1.5 \mathrm{~g} / \mathrm{kg}$ body weight) and blood glucose was measured by an ACCU-CHEK ${ }^{\circ}$ Active glucometer (Roche Diagnostics $\mathrm{GmbH}$, Mannheim, Germany).

\section{Biochemical analysis}

Serum total triacylglycerol (TG), cholesterol (TC), HDL-C, LDL-C, alanine aminotransferase (ALT), aspartate aminotransferase (AST) of C57BL/6J mice were measured by 
using Roche P800 chemistry analyzer (Hoffmann-La Roche Ltd., Switzerland) according to the manufacturer's instructions. The contents of MDA and SOD of serum and liver tissues were measured using commercially available kits (Nanjing Jiancheng Bioengineering Institute, Nanjing, China).

\section{Histochemical analysis}

After mice sacrifice, liver, epididymal fat was excised and weighted. A small piece of liver was fixed in $4.0 \%$ formalin solution for $48 \mathrm{~h}$. Then, liver samples were dehydrated, embedded in paraffin wax, sectioned and stained with hematoxylin and eosin (H\&E) according to standard procedure.

The morphology of hepatic cell was observed and photographed using a microscope (DM2700P, Leica, Germany). The histological analysis was performed according to the NAFLD scoring system, which was proposed by Kleiner et al. [20].

\section{Statistical analysis}

Data were presented as the mean \pm standard deviation ( $n=10$ per group). The statistical analysis was performed by one-way Analysis of Variance (ANOVA) combined with Duncan's Multiple Range test using SPSS package. $P<0.05$ was considered significant.

\section{Results and discussion}

\section{Characteristics of krill oil}

By using high quality of krill preserved by a novel procedure with a combination of heat pump drying and freezedrying process, $\mathrm{KO}$ was extracted by a subcritical extraction system with butane [13]. Properties of KO were analyzed and summarized in Tables 1 and 2, respectively. It contained a high amount of polyunsaturated fatty acids (PUFA) specific for omega-3 of DHA and EPA of $16.3 \%$ and 9.6\%, respectively. DHA and EPA have distinct effect on human health of cardiovascular protection and gain significant increase on demand as nutrient supplements in food industry. KO obtained through this procedure had a very similar fatty acid profiles as reported by others [21] and by Li et al., who used ethanol extraction method [22]. Another feature for $\mathrm{KO}$ was its high contents of phospholipids, a component as a nutrient supplement [23]. By using Jiang et al. method [16], the content of the $\mathrm{KO}$ was estimated about $62.30 \%$ triglycerides (TAG) and $28.68 \%$ of phospholipids and high astaxanthin about $248.4 \pm 5.2 \mathrm{mg} / \mathrm{kg}$ and tocopherols $\left(\mathrm{V}_{\mathrm{E}}\right)$ about $67.7 \pm 3.2 \mathrm{mg} / \mathrm{kg}$ (Table 1), respectively, are other factors for the healthy effect of diet supplement.

\section{Effect of KO supplementation on animal health}

It is known that oil extraction technology such as cold pressed and hot-pressed methods significantly affect the quality and nutrient contents of oils [24]. To further analyze the biological effect of $\mathrm{KO}$ produced by our novel procedure [13] on animal health, an animal feeding experiment was performed. High fat diet (HF diet) (20.0\% lard based) and with $5.0 \%$ substituent of $\mathrm{KO}$ (KO diet) were applied to feed C57BL/6 J mice for about 12 weeks (Table 3). As food was freely available to the mice, $\mathrm{KO}$ addition in the diet did not affect the amount of food intake (Table 4). Diet is one of critical environmental factors for development of obesity. Increased fat intakes and energy density in diets are associated with body weight gain related to obesity and metabolic diseases [25]. The mice fed with high fat diet increased body weight significantly and continued over the experimental feeding time (Fig. 1). However, the energy consumption did not show significant difference among various different diets groups, since the amounts of food intake for two high fat diets groups (HF diet and KO diet) were decreased about $20.0 \%$ compared with chow diet with a low-fat diet (NC diet) (Tables 3 and 4), supporting the notion of energy intensity of diet associated with body weight increase and obesity [26]. Furthermore, the lard based high fat diet contain more saturated fatty acids (Table 2), which could be more prone to obesity and other metabolic disorder such as cardiovascular diseases and hepatic steatosis [27] (as well in this study, see later), had significant more body weight gains and obese than that of NC group. This observation was consistent with high fat animal feeding model and support that balanced diet instead of fat/protein-rich diets are healthier to animals. Interestingly, mice fed with $\mathrm{KO}$ containing diet had less potential to increase body weight in comparison with lard based high fat feeding mice (Fig. 1). The body weight gain was probably from obesity as high increase of adipose weight such as epididymal fat (Table 4). HF group had gained about 2.7-fold vs 2.0-fold of $\mathrm{KO}$ diet group of epididymal fat weight in comparison to chow group. There was less significant change of other organ weights, such as livers which had about 10\% increase for HF diet group and similar for $\mathrm{KO}$ diet group compared with the chow diet group. As the only difference between HF and $\mathrm{KO}$ diets were $5 \%$ substitute of krill oil with lard, these results indicated that components from krill oils could play a benefit role or limit animal body weight gain (see later). This was interesting as $\mathrm{KO}$ supplementation in diet could benefit for body weight control in term of current energy rich diets with little restriction on food availability.

Table 1 Composition of KO

\begin{tabular}{llllll}
\hline & Triglycerides (\%) & Phospholipids (\%) & Astaxanthin $(\mathrm{mg} / \mathrm{kg})$ & Tocopherols $(\mathrm{mg} / \mathrm{kg})$ & Peroxide value $(\mathrm{meq} / \mathrm{kg})$ \\
\hline Content & $62.30 \pm 1.2$ & $28.68 \pm 1.0$ & $248.4 \pm 5.2$ & $67.7 \pm 3.2$ & $3.01 \pm 0.35$ \\
\hline
\end{tabular}


Table 2 Fatty acid compositions of $\mathrm{KO}$ and lard

\begin{tabular}{|c|c|c|}
\hline Fatty acid & KO (\%) & Lard (\%) \\
\hline $\mathrm{C} 12: 0$ & 0.2 & 0.1 \\
\hline C14:0 & 10.4 & 1.4 \\
\hline C16:0 & 21.5 & 32.8 \\
\hline C16:1 & 4.0 & 0.4 \\
\hline C17:0 & 2.0 & 0.0 \\
\hline C18:0 & 1.3 & 24.6 \\
\hline C18:1 & 19.4 & 37.3 \\
\hline C18:2 & 5.5 & 3.2 \\
\hline $\mathrm{aC} 18: 3$ & 9.2 & 0.2 \\
\hline C20:0 & 0.5 & 0.0 \\
\hline EPA C20:5 & 16.3 & 0.0 \\
\hline DHA C22:6 & 9.6 & 0.0 \\
\hline$\sum$ SFAs & 36.2 & 58.9 \\
\hline$\sum$ MUFAs & 23.4 & 40.9 \\
\hline$\sum n-3 P U F A s$ & 26.0 & 0.2 \\
\hline
\end{tabular}

SFA saturated fatty acids, MUFA monounsaturated fatty acids, PUFA polyunsaturated fatty acids

This result was consistent with others on effect of diets on the animal body weight change $[8,28]$.

\section{KO improved dyslipidemia and liver lipid accumulation}

The biochemical properties of serum were measured for their change of total triacylglycerol, cholesterol (Fig. 2) and liver functions (Tables 5, 6 and 7). Both total cholesterol and triacylglycerol were reduced after feeding with Krill oil containing diets in comparison with the HF diet.

Table 3 Composition of experimental diets

\begin{tabular}{llll}
\hline Components & NC diet & HF diet & KO diet \\
\hline Maize starch $(\mathrm{g} / \mathrm{kg})$ & 654.5 & 494.5 & 494.5 \\
Lard oil $(\mathrm{g} / \mathrm{kg})$ & 0.0 & 200.0 & 150.0 \\
$\mathrm{KO}(\mathrm{g} / \mathrm{kg})$ & 0.0 & 0.0 & 50.0 \\
Casein $(\mathrm{g} / \mathrm{kg})$ & 202.9 & 202.9 & 202.9 \\
Maltodextrin $(\mathrm{g} / \mathrm{kg})$ & 50.7 & 50.7 & 50.7 \\
Cellulose $(\mathrm{g} / \mathrm{kg})$ & 50.7 & 50.7 & 50.7 \\
DL-Methionine $(\mathrm{g} / \mathrm{kg})$ & 3.0 & 3.0 & 3.0 \\
Sucrose $(\mathrm{g} / \mathrm{kg})$ & 1.0 & 1.0 & 1.0 \\
Choline bitartrate $(\mathrm{g} / \mathrm{kg})$ & 1.0 & 1.0 & 1.0 \\
Sodium chloride $(\mathrm{g} / \mathrm{kg})$ & 2.0 & 2.0 & 2.0 \\
Calcium carbonate $(\mathrm{g} / \mathrm{kg})$ & 13.2 & 13.2 & 13.2 \\
Calcium bicarbonate $(\mathrm{g} / \mathrm{kg})$ & 10.1 & 10.1 & 10.1 \\
Cholesterol $(\mathrm{g} / \mathrm{kg})$ & 0.0 & 10.0 & 10.0 \\
Potassium citrate $(\mathrm{g} / \mathrm{kg})$ & 10.1 & 10.1 & 10.1 \\
Mineral mixture $(\mathrm{g} / \mathrm{kg})$ & 0.6 & 0.6 & 0.6 \\
Vitamin mixture $(\mathrm{g} / \mathrm{kg})$ & 0.2 & 0.2 & 0.2 \\
Energy density $(\mathrm{kcal} / 100 \mathrm{~g})$ & 364.4 & 454.9 & 454.9 \\
\hline
\end{tabular}

Table 4 Food intake and organ weight change of C57BL/6J mice fed for 12 weeks

\begin{tabular}{llll}
\hline & NC diet & HF diet & KO diet \\
\hline Food intake $\left(\mathrm{g}\right.$ animal $^{-1} \cdot$ day $\left.^{-1}\right)$ & $3.40 \pm 0.10^{\mathrm{a}}$ & $2.65 \pm 0.10^{\mathrm{b}}$ & $2.70 \pm 0.10^{\mathrm{b}}$ \\
Liver weight $(\mathrm{g})$ & $1.12 \pm 0.02^{\mathrm{a}}$ & $1.25 \pm 0.07^{\mathrm{b}}$ & $1.13 \pm 0.09^{\mathrm{a}}$ \\
Epididymal fat $(\mathrm{g})$ & $1.50 \pm 0.27^{\mathrm{a}}$ & $4.02 \pm 0.46^{\mathrm{b}}$ & $3.07 \pm 1.05^{\mathrm{c}}$ \\
\hline Values were means $\pm \mathrm{SD}(n=10)$; data that do not share the same superscript \\
letter(s) within a row were significantly different, $p<0.05$
\end{tabular}

However, the change for total triacylglycerol content was not significant. Further analysis the cholesterol contents of HDL-C and LDL-C in serum showed a reduction of LDL-C and little HDL-C change, indicated that effect of $\mathrm{KO}$ on total cholesterol reduction might attribute to the low LDL-C for disposal of cholesterol to the peripheral tissue and lead to improve lipid metabolism in high fat supplement diets.

LDL-C content of the mice was clearly an independent risk factor for atherosclerosis [29] and the rate of LDLC/HDL-C (Atherosclerosis-index, AI) was a more relevant risk indicator in lipid metabolism disorders [30]. Different diets affected AI with $\mathrm{KO}$ diet had better AI than lard based high fat diet, which followed the order: HF diets $(0.20)>\mathrm{KO}$ diets $(0.15)>\mathrm{NC}$ diets (0.04).

These results of the diets supplement of $\mathrm{KO}$ on animal health could decrease the risk of cardiovascular disease, implication on the cardiovascular protective effect of Krill oil which were consistent with other studies. Dietary Krill oil supplementation reduction of hypercholesterolemia has been reported in high fat fed mice [6,7], rat [28], rabbit [10] and human trial [11,31].

Lipid accumulation in hepatocytes was observed in the mice fed with high fat diets (Fig. 3). Hepatosteatosis induced by high fat diet was indicated with hepatic tissue staining and categorized with severity of hepatocyte ballooning (Table 5) [20]. The ballooning severity was significantly diminished and liver weights were also reduced

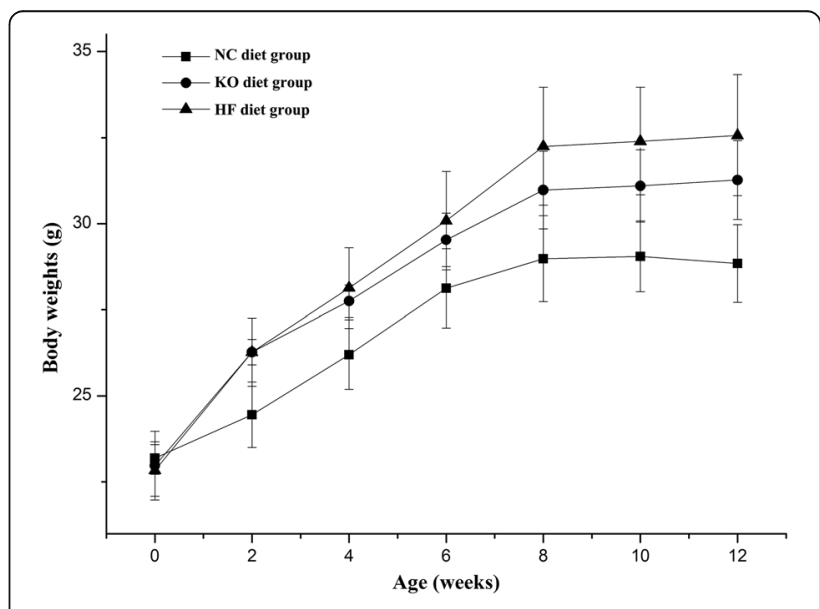

Fig. 1 The mice body weight change during feeding 

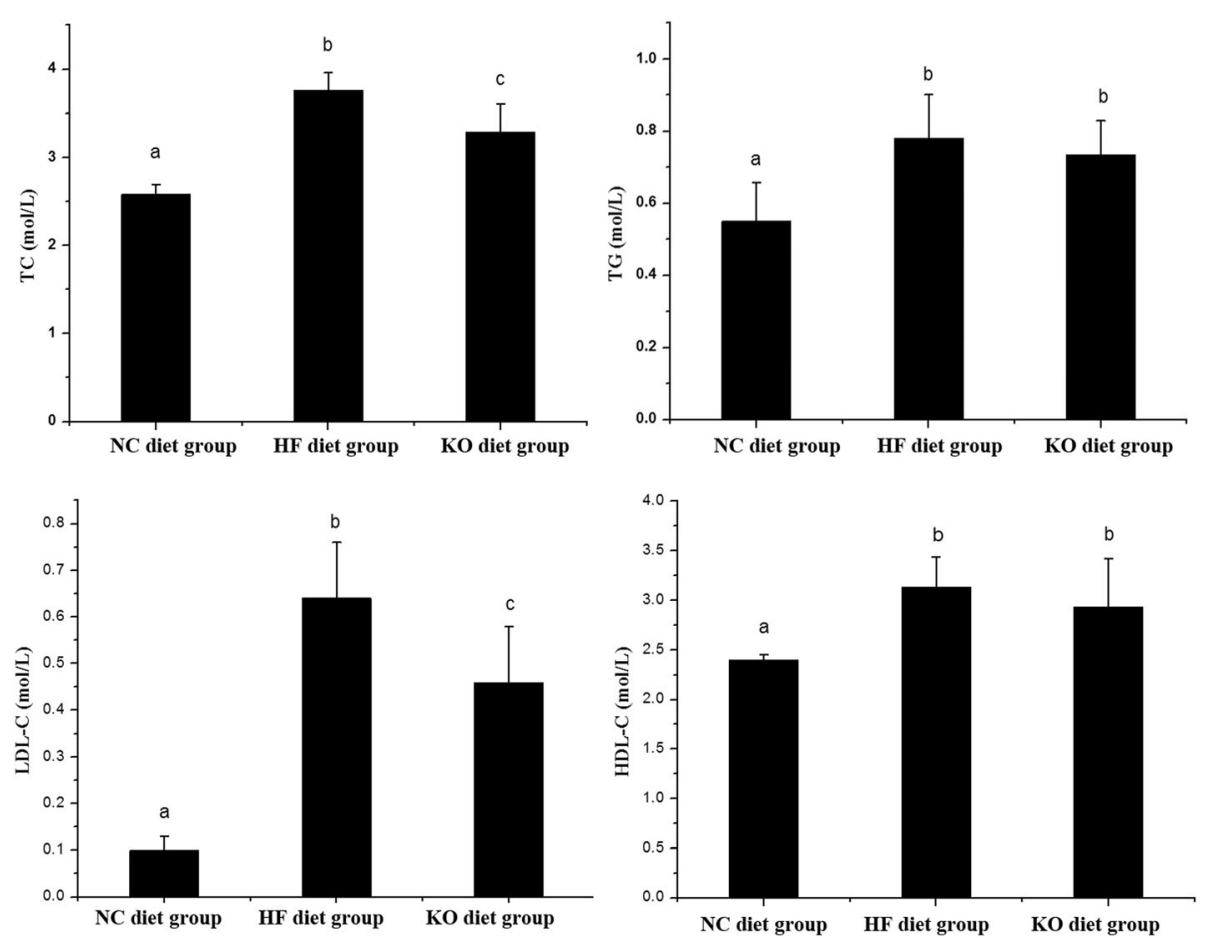

Fig. 2 TC, TG, LDL-C, and HDL-C of C57BL/6J mice fed with different diets. Means with different letters $(a, b, c)$ were significantly different from one another by Duncan's multiple-range test $(P<0.05)$

(Table 4) with feeding diets containing Krill oil. Krill oil contained a high amount of omega-3 fatty acids of EPA (16.34\%) and DHA (9.6\%), which are in both of triglyceride and phospholipids. These long chain omega-3 PUFA may attribute its beneficial health effect through alteration of hepatic gene expression, promotion of fatty acid oxidation on lipid metabolism, reduction of inflammation and improvement of insulin sensitivity [32]. Qi et al., reported that omega-3 PUFA containing diets decrease serum triglyceride concentrations in mice by reducing endogenous triglyceride synthesis [33]. KO could inhibit HF diet induced obesity and hepatic triacylglycerol accumulation in mice [34]. Omega-3 PUFA of phospholipids from fish oils suppress hepatic steatosis induced by high fat diet [35]. Compared with fish oil, with quantitatively similar doses of omega-3 PUFAs, KO seems to have a greater potential to promote lipid catabolism [36]. EPA and DHA and its metabolites such as DPA, play an important role in regulation of inflammation. Those Omega-3 fatty acids are also able to mediate anti-inflammatory effect through its metabolites such as resolvins and protectins and insulinsensitizing effect [37]. In liver, DPA interferes PPARa in the regulation of beta-oxidation and suppression of lipogenic genes. Omega-3 PUFAs involve the suppression of hepatic apoB production and its pool size. DHA unlike other saturated fatty acids such as palmitic acid and oleic acid has less potential to induce ER stress. DPA can inhibit thromboxane synthesis and cause acceleration of the lipoxygenase pathway to affect its biological effect such as inhibition of platelet aggregation [38]. All of these might indicate EPA and DHA beneficial effects are not limited to lipid metabolism as lipid energy resource but may be critical factors on lipid signaling regulation of lipid metabolism and metabolic diseases.

\section{Effect of KO on glucose metabolism}

High fat diets consumption could cause lipid accumulate in the body leading to obesity and other metabolic disorder

Table 5 Histological characteristics of liver from mice fed different diets for 12 weeks $^{a}$

\begin{tabular}{|c|c|c|c|c|c|}
\hline \multirow[t]{2}{*}{ Item } & \multirow[t]{2}{*}{ Definition } & \multirow[t]{2}{*}{ Score } & \multicolumn{3}{|c|}{ Percentage of each category in different groups ( $n=10$ per group) } \\
\hline & & & NC diet & HF diet & KO diet \\
\hline \multirow[t]{3}{*}{ Ballooning } & None & 0 & 100 & 0 & 80 \\
\hline & Few balloon cells & 1 & 0 & 10 & 20 \\
\hline & Many cells/prominent ballooning & 2 & 0 & 90 & 0 \\
\hline
\end{tabular}

${ }^{a}$ The histological diagnosis was performed according to the NAFLD scoring systemThe degree of liver cell injury was measured on the point scale 0-2, indicating ballooning in hepatocytes in our present study 
Table 6 SOD activity and MDA content in serum and liver in C57BL/6J mice

\begin{tabular}{|c|c|c|c|c|}
\hline \multirow[t]{2}{*}{ Diets group } & \multicolumn{2}{|l|}{ Serum } & \multicolumn{2}{|l|}{ Liver } \\
\hline & $\mathrm{MDA}(\mathrm{mmoL} / \mathrm{L})$ & Serum SOD (U/mL) & MDA (mmoL/mg protein) & Liver SOD (U/mLprotein) \\
\hline NC & $21.90 \pm 1.38 a$ & $137.91 \pm 10.39 a$ & $1.46 \pm 0.01 a$ & $28.32 \pm 1.29 a$ \\
\hline HF & $28.24 \pm 1.33 b$ & $114.35 \pm 8.48 b$ & $1.90 \pm 0.02 b$ & $24.51 \pm 1.01 b$ \\
\hline $\mathrm{KO}$ & $22.64 \pm 2.13 a$ & $155.38 \pm 5.32 c$ & $1.50 \pm 0.03 c$ & $29.70 \pm 1.34 a$ \\
\hline
\end{tabular}

Values are means \pm SD $(n=10)$; Means with different letters $(a, b, c)$ were significantly different from one another by Duncan's multiple-range test $(P<0.05)$

including glucose metabolism impair and insulin resistance [39]. Feeding with high fat diet, liver insulin resistance could be seen in three days whereas in peripheral tissues it would be about three weeks for insulin resistance [40, 41]. The high fat consumption effect on glucose metabolism was clearly evidenced in this study. As in Fig. 4a, the high fat diet feeding animals led to high fast blood glucose for about $9.8 \mathrm{mmol} / \mathrm{L}$ for HF diet in contrast to $9.3 \mathrm{mmol} / \mathrm{L}$ of chow diet of NC. With the substituent of $5.0 \%$ lard with Krill oil, the fast blood glucose would reduce up to $8.5 \mathrm{mmol} / \mathrm{L}$, which was even more pronounced $(10 \%)$ than the normal chow group.

Furthermore, effect of Krill oil diets was investigated by using GTTs (Fig. 4c). There was a $13.0 \%$ of decrease of AUC of the mice fed with $\mathrm{KO}$ containing diet, indicating that supplementation of $\mathrm{KO}$ would improve animal glucose metabolism. These results were supported with other studies in animal feeding with Krill oil in rabbit [10], mice [6, 42] and human trial for food supplementation [11], indicating that Krill oil and fish oil supplementation with high content of EPA and DHA indeed could benefit to improving glucose metabolism.

\section{Effect of KO on oxidative stress}

High fat diet feeding to animal significantly induced MDA production, an indicator of lipid peroxidation, and a biomarker of oxidative damage to tissues. In contrast, the SOD activities, capable of removal free radicals in organism, correspondingly, decreased, as in Table 6 for this study. Both in serum and liver tissue, the MDA contents significantly increased with SOD activities diminished. Interestingly, addition of Krill oil in the diet greatly improved and restored the SOD level to that of chow feeding animals. These results likely indicated that there was an oxidative stress in animals particularly in liver due to high fat diet feeding. This was also supported by the increased ALT enzymatic activities in HF

Table 7 Serum ALT and AST activities of C57BL/6 Jmice

\begin{tabular}{lll}
\hline Diets group & ALT $(\mathrm{mmol} / \mathrm{L})$ & AST $(\mathrm{mmol} / \mathrm{L})$ \\
\hline $\mathrm{NC}$ & $25.82 \pm 2.56 \mathrm{a}$ & $116.54 \pm 10.97 \mathrm{a}$ \\
$\mathrm{HF}$ & $33.84 \pm 3.68 \mathrm{~b}$ & $116.86 \pm 8.73 \mathrm{a}$ \\
$\mathrm{KO}$ & $28.66 \pm 2.85 \mathrm{a}$ & $126.25 \pm 12.60 \mathrm{a}$ \\
\hline
\end{tabular}

Means with different letters $(a, b)$ were significantly different from one another by Duncan's multiple-range test $(P<0.05)$
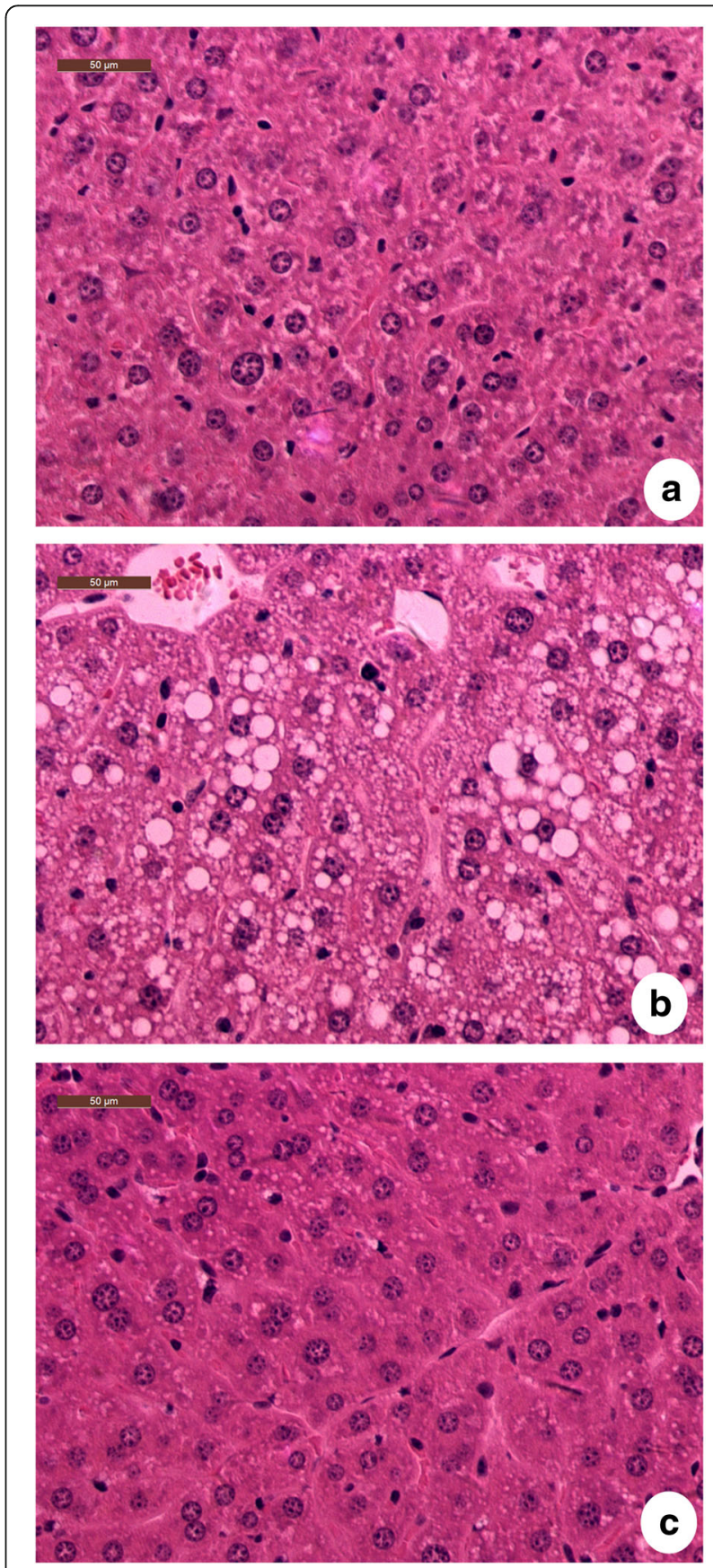

Fig. 3 Morphological feature of liver by H\&E staining. a NC diet group; b HF diet group; c KO diet group 


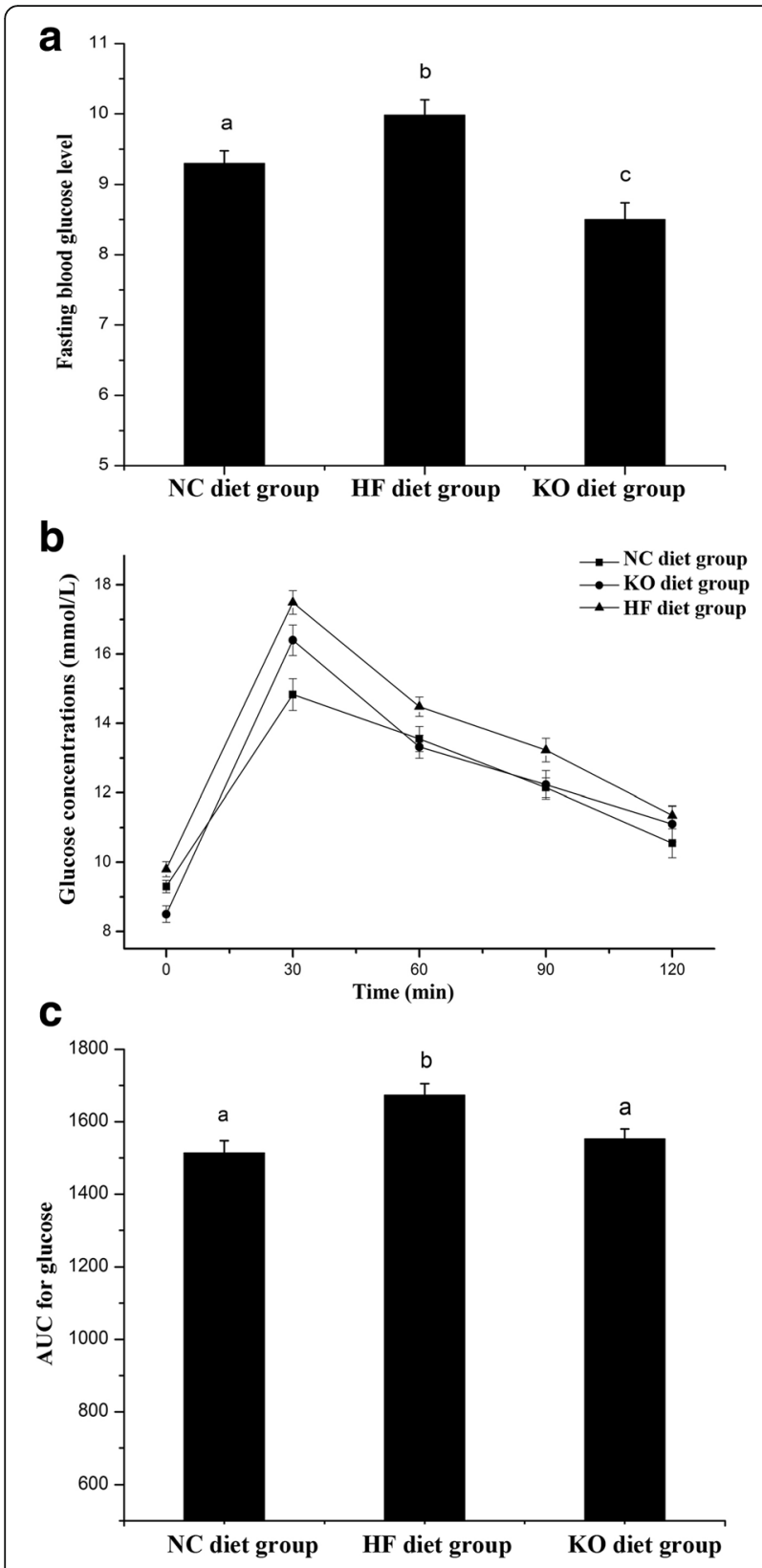

Fig. 4 Glucose metabolism change after fed with different diets. a Fasting blood glucose level; b GTs for male C57BL/6J mice after 12 weeks on control or different HF diet; c AUC for blood glucose over $2 \mathrm{~h}$ in GTTs

group (Table 7). This oxidative stress could be restored by Krill oil feeding might be due to high contents of astaxanthin and tocopherols as well (Table 1). Astaxanthin has high antioxidant capacity which is about ten times greater than $\beta$-carotene [43]. Tocopherols are vital for stabilizing the unsaturated fatty acids of the oils against oxidative deterioration [44]. In addition, phospholipids can act as an enhancer for the $\mathrm{V}_{\mathrm{E}}$ to inhibit the autoxidation [45]. Hence, Krill oil used in this study and prepared from our novel procedure [13], contained abundant of astaxanthin and phospholipids might contribute to their high capacity for ROS removal and antioxidant activities. Krill oil supplementation in diet could also relieve oxidative stress and DNA damages in obese rats [46]. In addition, the metabolites from the high content of EPA and DHA in Krill oil might also contribute to the effect of anti-oxidative and anti-inflammation in the high fat diets feeding animal. The results from this study clearly indicated that the Krill oil used by this study could be good food supplement to animal health.

\section{Conclusion}

The beneficial effect of Krill oil used in this study by a novel procedure was investigated. It was clearly demonstrated that the Krill oil containing a high content of polyunsaturated fatty acids EPA and DHA and astaxanthin could significantly improve dyslipidemia, fatty liver, and glucose metabolism in C57BL/6J mice.

\section{Abbreviations}

ALT: Alanine aminotransferase; AOCS: American Oil Chemists' Society; AST: Aspartate aminotransferase; AUC: Area under the curve; DHA: Docosahexaenoic acid; DPA: Docosapentenoic acid; EPA: Eicosapentaenoic acid; GTTs: Glucose tolerance tests; H\&E: Hematoxylin and eosin; HDL-C: High density lipoprotein- cholesterol; HF: High fat; KO: Antarctic krill oil; LDL-C: Low density lipoprotein- cholesterol; MDA: Malondialdehyde; MUFA: Monounsaturated fatty acids; NC: Normal control; PUFA: Polyunsaturated fatty acids; SFA: Saturated fatty acids; SOD: Superoxide dismutase; TC: Cholesterol; TG: Triacylglycerol

\section{Acknowledgements}

Not applicable

\section{Funding}

This work was supported by the National Natural Science Foundation of China (31571878), the Public Sector Research Special Food (201313011-7-3), Beijing Municipal Science and Technology Project (D151100004015003).

Availability of data and materials

Not applicable

\section{Authors' contributions}

$P C$ and $Y L$ conceived and designed the experiments; $L Z, H C$ and DS performed the experiments; RF and DS analyzed the data; DS and PC wrote the paper. All authors read and approved the final manuscript.

\section{Ethics approval}

All protocols for animal experiments were approved by the Animal Care and Use Committee of Jiangnan University (JN No. 30 2015). They were in accordance with the Guide for the Care and Use of Laboratory Animals issued by the Ministry of Science and Technology of the People's Republic of China in 2006.

Consent for publication

Not applicable

Competing interests

The authors declare that they have no competing interests.

\section{Publisher's Note}

Springer Nature remains neutral with regard to jurisdictional claims in published maps and institutional affiliations. 
Received: 5 July 2017 Accepted: 30 October 2017

Published online: 21 November 2017

\section{References}

1. Biddinger SB, Kahn CR. From mice to men: insights into the insulin resistance syndromes. Annu Rev Physiol. 2006;68:123-58.

2. Ghasemifard S, Turchini GM, Sinclair AJ. Omega-3 long chain fatty acid "bioavailability": a review of evidence and methodological considerations. Prog Lipid Res. 2014;56:92-108.

3. Salem N Jr, Kuratko CN. A reexamination of krill oil bioavailability studies. Lipids Health Dis. 2014;13:137.

4. Gigliotti JC, Davenport MP, Beamer SK, Tou JC, Jaczynski J. Extraction and characterisation of lipids from Antarctic krill (Euphausia superba). Food Chem. 2011;125:1028-36.

5. Aune D, Keum N, Giovannucci E, Fadnes LT, Boffetta P, Greenwood DC, Tonstad S, Vatten LJ, Riboli E, Norat T. Nut consumption and risk of cardiovascular disease, total cancer, all-cause and cause-specific mortality: a systematic review and dose-response meta-analysis of prospective studies. BMC Med. 2016;14:207

6. Tandy S, Chung RW, Wat E, Kamili A, Berge K, Griinari M, Cohn JS. Dietary krill oil supplementation reduces hepatic steatosis, glycemia, and hypercholesterolemia in high-fat-fed mice. J Agric Food Chem. 2009:57:9339-45.

7. Tillander V, Bjorndal B, Burri L, Bohov P, Skorve J, Berge RK, Alexson SE. Fish oil and krill oil supplementations differentially regulate lipid catabolic and synthetic pathways in mice. Nutr Metab (Lond). 2014;11:20.

8. Yang G, Lee J, Lee S, Kwak D, Choe W, Kang I, Kim SS, Ha J. Krill oil supplementation improves dyslipidemia and lowers body weight in mice fed a high-fat diet through activation of AMP-activated protein kinase. J Med Food. 2016;19:1120-9.

9. Bjorndal B, Vik R, Brattelid T, Vigerust NF, Burri L, Bohov P, Nygard O, Skorve J, Berge RK. Krill powder increases liver lipid catabolism and reduces glucose mobilization in tumor necrosis factor-alpha transgenic mice fed a high-fat diet. Metabolism. 2012;61:1461-72.

10. Ivanova Z, Bjorndal B, Grigorova N, Roussenov A, Vachkova E, Berge K, Burri L, Berge R, Stanilova S, Milanova A, et al. Effect of fish and krill oil supplementation on glucose tolerance in rabbits with experimentally induced obesity. Eur J Nutr. 2015:54:1055-67.

11. Lobraico JM, DiLello LC, Butler AD, Cordisco ME, Petrini JR, Ahmadi R. Effects of krill oil on endothelial function and other cardiovascular risk factors in participants with type 2 diabetes, a randomized controlled trial. BMJ Open Diabetes Res Care. 2015;3:e000107.

12. Joob B, Wiwanitkit V. Krill oil: new nutraceuticals. J Coast Life Med. 2015;3:669-70.

13. Sun D, Cao C, Li B, Chen H, Cao P, Li J, Liu Y. Study on combined heat pump drying with freeze-drying of Antarctic krill and its effects on the lipids. J Food Process Eng. 2017; DOl:10.1111/jfpe.12577.

14. AOCS: Peroxide Value Acetic Acid-Chloroform Method. AOCS Official Method Cd 8-53: 1998, Official Methods and Recommended Practices of the American Oil Chemists.

15. AOCS. Preparation of methyl esters of fatty acids. In: AOCS official method Ce 2-66, vol. 1997. Champaign (IL): AOCS Press; 1999.

16. Jiang XF, Jin QZ, SM W, Wang XG. Contribution of phospholipids to the formation of fishy off-odor and oxidative stability of soybean oil. Eur Food Res Technol. 2016:118:603-11.

17. Paquot $C$, Hautfenne A. Determination of tocopherols and tocotrienols in vegetable oils and fats by HPLC. Method 2, 432 Standard methods for the analysis of oils, fats and derivatives. Oxford, UK: IUPAC, revised and enlarged[J]. Blackwell Scientific Publications; 1992.

18. Tolasa S, Cakli S, Ostermeyer U. Determination of astaxanthin and canthaxanthin in salmonid. Eur Food Res Technol. 2005:221:787-91.

19. Metusalach BJA, Shahidi F. Effects of stocking density on colour characteristics and deposition of carotenoids in cultured Arctic charr (Salvelinus alpinus). Food Chem. 1997;59:107-14.

20. Kleiner DE, Brunt EM, Van Natta M, Behling C, Contos MJ, Cummings OW, Ferrell LD, Liu YC, Torbenson MS, Unalp-Arida A, et al. Design and validation of a histological scoring system for nonalcoholic fatty liver disease. Hepatology. 2005;41:1313-21

21. Liu J, Feng D, Su X, Li X, Liu Y. Optimization of formula for Antartic krill oil soft capsules Shell. Progress Fishery Sci. 2014;35:141-4.

22. Li DM, Zhou DY, Zhu BW, Chi YL, Sun LM, Dong XP, Qin L, Qiao WZ, Murata $Y$. Effects of krill oil intake on plasma cholesterol and glucose levels in rats fed a high-cholesterol diet. J Sci Food Agric. 2013;93:2669-75.
23. Ding $L$, Zhang $L$, Wen $M$, Che $H$, Du L, Wang J, Xue C, Xu J, Wang $Y$. Eicosapentaenoic acid-enriched phospholipids improve atherosclerosis by mediating cholesterol metabolism. J Funct Foods. 2017;32:90-7.

24. Oliveras-López MJ, Berná G, Carneiro EM, dISH L-G, Martín F, López MC. An extra-virgin olive oil rich in polyphenolic compounds has antioxidant effects in OF1 mice. J Funct Foods. 2008;138:1074-8.

25. Munsters MJ, Saris WH. Body weight regulation and obesity: dietary strategies to improve the metabolic profile. Annu Rev Food Sci Technol. 2014;5:39.

26. Dell'Italia L, Meng QC, Balcells E, Wei CC, Palmer R, Hageman GR, Durand J, Hankes GH, Oparil S. Compartmentalization of angiotensin II generation in the dog heart. Evidence for independent mechanisms in intravascular and interstitial spaces. J Clin Invest. 1997;100:253-8.

27. Baum SJ, Kris-Etherton PM, Willett WC, Lichtenstein AH, Rudel LL, Maki KC, Whelan J, Ramsden CE, Block RC. Fatty acids in cardiovascular health and disease: a comprehensive update. J Clin Lipidol. 2012;6:216-34.

28. Ferramosca A, Conte A, Burri L, Berge K, De Nuccio F, Giudetti AM, Zara V. A krill oil supplemented diet suppresses hepatic steatosis in high-fat fed rats. PLoS One. 2012;7:e38797.

29. Roever L, Biondi-Zoccai G, Chagas AC. Non-HDL-C vs. LDL-C in predicting the severity of coronary atherosclerosis. Heart Lung Circ. 2016;25:953-4.

30. Kastelein JJ, van der Steeg WA, Holme I, Gaffney M, Cater NB, Barter P, Deedwania P, Olsson AG, Boekholdt SM, Demicco DA, et al. Lipids, apolipoproteins, and their ratios in relation to cardiovascular events with statin treatment. Circulation. 2008:117:3002-9.

31. Albert BB, Derraik JG, Brennan CM, Biggs JB, Garg ML, Cameron-Smith D, Hofman PL, Cutfield WS. Supplementation with a blend of krill and salmon oil is associated with increased metabolic risk in overweight men. Am J Clin Nutr. 2015;102:49-57.

32. Townsend SA, Newsome PN: Non-alcoholic fatty liver disease in $2016 \mathrm{Br}$ Med Bull 2016, 119:143.

33. Qi K, Fan C, Jiang J, Zhu H, Jiao H, Meng Q, Deckelbaum RJ. Omega-3 fatty acid containing diets decrease plasma triglyceride concentrations in mice by reducing endogenous triglyceride synthesis and enhancing the blood clearance of triglyceride-rich particles. Clin Nutr. 2008;27:424-30.

34. Lee MF, Lai CS, Cheng AC, Hou JS, Badmaev V, Ho CT, Pan MH. Krill oil and xanthigen separately inhibit high fat diet induced obesity and hepatic triacylglycerol accumulation in mice. J Func Foods. 2015:19:913-21.

35. Rossmeisl M, Medrikova D, van Schothorst EM, Pavlisova J, Kuda O, Hensler M, Bardova K, Flachs P, Stankova B, Vecka M, et al. Omega-3 phospholipids from fish suppress hepatic steatosis by integrated inhibition of biosynthetic pathways in dietary obese mice. Biochim Biophys Acta. 2014;1841:267-78.

36. Vigerust NF, Bjørndal B, Bohov P, Brattelid T, Svardal A, Berge RK. Krill oil versus fish oil in modulation of inflammation and lipid metabolism in mice transgenic for TNF-a. Eur J Nutr. 2013:52:1315-25.

37. Oh DY, Talukdar S, Bae EJ, Imamura T, Morinaga H, Fan W, Li P, Lu WJ, Watkins SM, Olefsky JM. GPR120 is an omega-3 fatty acid receptor mediating potent anti-inflammatory and insulin-sensitizing effects. Cell. 2010;142:687-98.

38. Scorletti E, Byrne CD. Omega-3 fatty acids, hepatic lipid metabolism, and nonalcoholic fatty liver disease. Ann Rev Nutr. 2013;33:231-48.

39. Storlien LH, Kraegen EW, Chisholm DJ, Ford GL, Bruce DG, Pascoe WS. Fish oil prevents insulin resistance induced by high-fat feeding in rats. Science. 1987;237:885-8

40. Chiang YF, Shaw HM, Yang MF, Huang CY, Hsieh CH, Chao PM. Dietary oxidised frying oil causes oxidative damage of pancreatic islets and impairment of insulin secretion, effects associated with vitamin E deficiency. Br J Nutr. 2011;105:1311-9.

41. Ringseis R, Eder K. Regulation of genes involved in lipid metabolism by dietary oxidized fat. Mol Nutr Food Res. 2011;55:109-21.

42. Tillander $V$, Burri $L$, Alexson S. Fish oil and krill oil differentially regulate gene expression. Chem Phys Lipids. 2010;163:S31-1.

43. Mikova K. In: Pokorny J, Yanishlieva N, Gordon M, editors. Antioxidants in Food: Practical Applications, vol. 267-283. Cambridge, England: Woodhead publishing, Itd.; 2011.

44. Kamal-Eldin A, Appelqvist LA. The chemistry and antioxidant properties of tocopherols and tocotrienols. Lipids. 1996;31:671-701.

45. Hudson BJF, Ghavami M. Phospholipids as antioxidant synergists for tocopherols in the autoxidation of edible oils. LWT Food Sci Technol. 1984;

46. Mellouk Z, Agustina M, Ramirez M, Pena K, Arivalo J. The therapeutic effects of dietary krill oil (Euphausia superba) supplementation on oxidative stress and DNA damages markers in cafeteria diet-overfed rats. Ann Cardiol Angeiol (Paris). 2016;65:223-8. 